\title{
Chronic suppression of insulin by diazoxide alters the activities of key enzymes regulating hepatic gluconeogenesis in Zucker rats
}

\author{
Ramin Alemzadeh, Sidney Holshouser, Pam Massey ${ }^{1}$ and John Koontz ${ }^{1}$ \\ Department of Pediatrics, University of Tennessee, Graduate School of Medicine, Knoxville, USA and ${ }^{1}$ Department of Biochemistry and Cellular and \\ Molecular Biology, University of Tennessee, Knoxville, USA \\ (Correspondence should be addressed to R Alemzadeh who is now at Section of Pediatric Endocrinology and Metabolism, Medical College of Wisconsin, \\ MACC Fund Research Center, 8701 Watertown Plank Road, P.O. Box 26509, Milwaukee, Wisconsin 53226-0509, USA; Email: ralemzad@mcw.edu)
}

\begin{abstract}
Objectives: Chronic attenuation of hyperinsulinemia by diazoxide (DZ), an inhibitor of glucosemediated insulin secretion, improved insulin sensitivity and glucose tolerance and caused downregulation of lipid metabolizing enzymes in adipose tissue and decreased the rate of weight gain in mildly hyperglycemic obese Zucker rats. Since the liver plays a central role in glucose homeostasis, we studied the effect of chronic insulin suppression on key insulin-sensitive enzymes regulating hepatic gluconeogenesis.

Methods: DZ (150 mg/kg per day) or vehicle (control) was administered to 7-week-old female obese and lean Zucker rats for a period of 4 weeks.

Results: DZ-treated animals showed lower fasting plasma insulin levels $(P<0.001)$ than their controls. Plasma glucose levels were lower in DZ obese rats than in controls $(P<0.001)$, without a significant change in DZ lean animals. DZ had no effect on glucose transporter 2 protein expression in either strain. DZ treatment resulted in lower hepatic glucokinase $(P<0.001)$ and glucose-6phosphatase $(P<0.0001)$ and phosphoenolpyruvate carboxykinase (PEPCK) activities only in obese rats compared with controls $(P<0.001)$. However, DZ-treated lean rats demonstrated higher PEPCK activity than controls $(P<0.002)$. DZ-treated animals demonstrated enhanced hepatic glucose-6-phosphate content $(P<0.01)$, glycogen synthase activity $(P<0.0001)$ and glycogen content $(P<0.02)$ compared with their controls despite increased hepatic glycogen phosphorylase a activity in these animals $(P<0.02)$.

Conclusions: Chronic suppression of hyperinsulinemia in obese Zucker rats by DZ decreased the activities of key enzymes regulating hepatic gluconeogenesis, implying that attenuation of the hyperinsulinemic state by DZ may be therapeutically beneficial.
\end{abstract}

European Journal of Endocrinology 146 871-879

\section{Introduction}

Abnormalities in glucose metabolism and insulin resistance are common features of obesity and type 2 diabetes mellitus (DM) in humans and experimental animals but the nature of the mechanisms responsible for these abnormalities remains controversial (1-3). Both impaired glucose utilization by peripheral and hepatic tissue and increased hepatic glucose output are thought to be important contributory factors to these syndromes (4-6). Insulin deficiency in type 1 DM and the insulin resistance in obesity and type 2 DM lead to a decrease in glucose utilization by the liver, muscle, and adipose tissue and to an increase in hepatic glucose production $(7,8)$.
The liver plays a central role in maintaining glucose homeostasis. Glucose transport and phosphorylation are the first steps in glucose utilization (9). In the non-diabetic state, glucose transporter 2 (Glut-2), a member of the glucose transporter family, provides glucose to hepatocytes at a rate that is 100 times greater than the rate of phosphorylation by glucokinase (GK), a key enzyme in the regulation of glucose utilization (10). Hepatic GK activity is not inhibited by physiological concentrations of glucose-6-phosphate (11) but is regulated mainly due to changes in the transcription of its gene and its regulatory protein (12). Insulin increases and glucagon inhibits GK gene transcription, and these effects are not glucose-dependent $(13,14)$. The main role of insulin in the activation of glycolytic 
genes appears to be the stimulation of GK synthesis leading to increased glucose phosphorylation. Furthermore, increasing glucose concentration increases the amount of free GK, due to translocation of GK from the nucleus to cytoplasm (15). The cytosolic form of phosphoenolpyruvate carboxykinase (PEPCK) and glucose-6-phosphatase (G-6-Pase), which catalyzes the hydrolysis of glucose-6-phosphate (G-6-P) to glucose, are the key enzymes controlling gluconeogenesis and glucose output from the liver $(16,17)$. The activity of G-6-Pase is markedly regulated by insulin (18) which plays a major role in the long-term suppression of hepatic glucose production in the fed state but appears to have little or no effect on G-6-Pase activity in the fasted state (19). The activity of PEPCK is controlled primarily at the level of transcription, being stimulated by glucagon and inhibited by insulin $(17,20)$.

Genetically obese Zucker rats are characterized by hyperinsulinemia and peripheral insulin resistance with normal or slightly elevated fasting blood glucose levels (21). Persistent hyperinsulinemia and insulin resistance in obese Zucker rats is believed to increase simultaneously activities of glycolytic and gluconeogenic enzymes even in the fasted state, leading to enhanced glycolysis and lipogenesis (22). Chronic attenuation of hyperinsulinemia by diazoxide (DZ), an inhibitor of glucose-mediated insulin secretion, has been shown to cause enhanced insulin sensitivity in isolated adipocytes, down-regulation of lipid metabolizing enzymes in adipose tissue, improved glucose tolerance and weight reduction in obese Zucker rats (23-25). To investigate the effect of chronic insulin suppression on hepatic glucose metabolism, we measured the Glut-2 protein expression and the activities of key insulin-sensitive enzymes regulating hepatic gluconeogenesis namely GK, G-6-Pase, active glycogen synthase (GSa), active glycogen phosphorylase (GPa) and PEPCK in diazoxide-treated obese and lean Zucker rats.

\section{Research design and methods}

\section{Experimental animals, dietary and diazoxide treatment}

Seven-week-old female Zucker obese $(f a / f a)$ and lean $(\mathrm{Fa} /$ ? $)$ rats were obtained at 6 weeks of age from Charles River Laboratory (Wilmington, MA, USA). The animals were provided with rat chow, Rodent diet 22/5 (W) 8640 (Teklad Harlan Laboratories, Madison, WI, USA), and water available ad libitum. Obese and lean rats were divided into two subgroups: DZ treated and control subgroups. Diazoxide $(150 \mathrm{mg} / \mathrm{kg}$ per day) was administered in two doses daily by gavage using Proglycem suspension $(50 \mathrm{mg} / \mathrm{ml}$, kindly provided by Baker-Norton Pharmaceuticals, Miami, FL, USA). The control groups were treated with an equivalent volume of vehicle suspension twice daily. Studies lasted for a period of 4 weeks. Rats were weighed twice weekly to determine weight gain. Food consumption was measured while animals were in separate metabolic cages during the last two weeks of treatment. At the end of the 4-week period and after an overnight fast $(12 \mathrm{~h})$, rats were anesthetized with an intramuscular injection of ketamine ( 65 to $100 \mathrm{mg} / \mathrm{kg}$ body weight $(\mathrm{BW})$ ). Blood was drawn into heparinized tubes by cardiac puncture and plasma was frozen. Hepatic tissue was excised and rapidly frozen in liquid nitrogen. Frozen livers were stored in labeled containers at $-80^{\circ} \mathrm{C}$ pending enzyme studies and metabolic determinations. Animal procedures were reviewed and approved by the University of Tennessee Animal Care and Use Committee.

\section{Assays}

Plasma glucose and insulin assays Glucose was measured by the glucose oxidase method (Sigma Chemical, St Louis, MO, USA). Insulin concentration was determined by radioimmunoassay using a double-antibody method (LINCO Research, St Louis, MO, USA).

Plasma cholesterol, triglycerides and free fatty acids (FFA) Cholesterol and triglycerides levels were measured by an enzymatic method (Sigma Diagnostics, St Louis, MO, USA). Plasma FFA were determined by an enzymatic colorimetric method (Wako Chemicals, Richmond, VA, USA).

Glucose transporter-2 immunoblots Several different amounts of liver membrane protein (26) for Glut-2 were tested in immunoblotting to optimize the detection system. Protein samples were run on $12 \% / 0.75 \mathrm{~mm}$ SDS-PAGE gel and blotted to a PVDF membrane (Millipore, Bedford, MA, USA) using a Trans-Blot Semi-Dry Electrophoretic Transfer Cell (Bio-Rad, Hercules, CA, USA). The membrane was then blocked with 10\% non-fat dry milk for Glut-2. The blot was then probed with Glut-2 antibody (a kind gift from S W Cushman, National Institutes of Health, Bethesda, MD, USA) using the Aurora Western Blot Chemiluminescent Detection System (ICN, Costa Mesa, CA, USA). The secondary antibody was a peroxidase-conjugated affinity pure donkey anti-rabbit IgG (Jackson Immuno-Research). The membrane was then exposed to Biomax ML film (Kodak) from $15 \mathrm{~s}$ to 2 min. The intensity of the bands was measured by densitometry.

\section{Enzyme assays and metabolites}

Glucokinase assay Hepatic GK activity was determined using a continuous spectrophotometric method as previously described (27). Pieces of liver weighing $1000 \mathrm{mg}$ were minced with scissors and homogenized 
in a standard buffer. The homogenate was centrifuged and the supernatant was used for GK assay. The GK activity was calculated as the difference between glucose phosphorylation capacity at 100 and $0.5 \mathrm{mmol} / \mathrm{l}$ glucose and hexokinase activity as the glucose phosphorylating capacity at $0.5 \mathrm{mmol} / \mathrm{l}$ glucose. Protein content of fractions was estimated using the Lowry method (28).

Glucose-6-phosphatase Two methods were used to assay G-6-Pase. In the first, G-6-Pase cleavage by microsomal fractions incubated at $37^{\circ} \mathrm{C}$ and $\mathrm{pH} 7.5$ in Tris- $\mathrm{HCl}$ buffer was measured by the amount of $\mathrm{P}_{\mathrm{i}}$ liberated (29). In studies using liver homogenates and in work with concentrated microsomal membranes, phosphates from the tissue interfered with the assay of G-6-Pase based on $\mathrm{P}_{\mathrm{i}}$ release. In these studies, release of $\left[{ }^{14} \mathrm{C}\right]$ glucose from $\left[{ }^{14} \mathrm{C}\right] \mathrm{G}-6-\mathrm{P}$ was measured as previously described (30). $\beta$-Glycerophosphate was added to the buffer to inhibit nonspecific phosphatase activity. The specificity of the assay was confirmed by using $\left[{ }^{14} \mathrm{C}\right]$ glucose-1-phosphate as substrate.

Phosphoenolpyruvate carboxykinase assay The cytosolic fraction from liver homogenates was separated by ultracentrifugation for PEPCK assay. Enzymatic activity was assayed in the reverse direction (carboxylation of phosphoenolpyruvate to form oxaloacetic acid (OAA)) in the presence of deoxyguanosine diphosphate as previously described (31). PEPCK activity is expressed as nmol OAA $/ \mathrm{min} / \mathrm{g}$ liver.

Glycogen synthase assay The GS assay procedure was a modification of a method previously described by Thorburn et al. (32). The GS activity was calculated using the method described by Nuttall and Gannon (33). Frozen liver samples were homogenized and enzyme activity was measured by the incorporation of $\left[\mathrm{U}-{ }^{14} \mathrm{C}\right]$ uridine diphosphate glucose (UDPG) (New England Nuclear-Dupont, Boston, MA, USA) into glycogen in the presence of a low substrate concentration of UDPG for active GS and a high concentration for determination of total GS activity.
Glycogen phosphorylase a assay The GPa activity was assayed in the direction of glycogen synthesis as described by Nuttall et al. (34). The assay was conducted at $30{ }^{\circ} \mathrm{C}$ and initiated by adding a reaction mixture containing $2[\mathrm{~N}$-morpholino]ethanesulfonic acid (pH 6.3), glucose-1-phosphate, caffeine, glycogen and ${ }^{14} \mathrm{C}$-labeled glucose-1-phosphate diluted hepatic tissue extract. The reaction was terminated at $20 \mathrm{~min}$ by placing aliquots of reaction mixture on the anionexchange columns, washing the columns with water and counting the eluate. The hepatic GPa enzyme activity is expressed in $\mu \mathrm{mol}$ of substrate transformed per min per $g$ tissue.

Glucose-6-phosphate, liver glycogen and xylulose5-phosphate (X-5-P) determinations The hepatic G-6-P content was measured using a previously described method and was expressed as nmol/g liver (35). The glycogen content was measured using the $\alpha$-amylglucosidase method (36). The values were expressed as $\mathrm{mg}$ glycogen/g liver. The hepatic X-5-P was determined as previously described by Casazza and Veech (37). The values were expressed as nmol/g liver.

\section{Statistical analysis}

The reported values represent the means \pm s.E. Statistical comparisons between subgroups was assessed by two-way analysis of variance (ANOVA) and Dunnett's and Tukey's tests. A $P$ value less than 0.05 was considered statistically significant.

\section{Results}

\section{Effect of diazoxide on food intake and body weight}

Table 1 shows weight and food intake in obese and lean Zucker rats. Control obese rats exhibited higher initial weight and greater weight gain over the 4-week observation period than lean animals $(P<0.001)$. Final body weight and average weight gain among DZ

Table 1 Weight and food intake data in obese and lean Zucker rats. Data are means \pm S.E.

\begin{tabular}{|c|c|c|c|c|c|}
\hline Subgroup & $n$ & $\begin{array}{l}\text { Initial weight } \\
(\mathrm{g})\end{array}$ & $\begin{array}{l}\text { Final weight } \\
(\mathrm{g})\end{array}$ & $\begin{array}{l}\text { Weight gain } \\
\text { (per } 100 \text { g BW) }\end{array}$ & $\begin{array}{c}\text { Cal/day } \\
(\text { per } 100 \mathrm{~g} \mathrm{BW})\end{array}$ \\
\hline DZ obese & 8 & $203 \pm 4$ & $274 \pm 6$ & $26 \pm 3^{a}$ & $28 \pm 3^{a}$ \\
\hline C obese & 8 & $210 \pm 5$ & $335 \pm 6$ & $38 \pm 2$ & $47 \pm 2$ \\
\hline DZ lean & 8 & $144 \pm 1$ & $182 \pm 2$ & $21 \pm 1$ & $31 \pm 2$ \\
\hline C lean & 8 & $148 \pm 2$ & $196 \pm 3$ & $24 \pm 1$ & $34 \pm 2$ \\
\hline \multicolumn{6}{|l|}{$P$ value } \\
\hline Obese vs lean & & $<0.001$ & $<0.001$ & $<0.001$ & $<0.001$ \\
\hline
\end{tabular}

Data were analyzed by two-way ANOVA.

${ }^{a}$ DZ obese vs C obese.

NS, not significant. 
obese animals was reduced compared with control obese rats $(P<0.001)$, whereas DZ treatment had no effect on the rate of weight gain in lean animals. When food intake was measured during the treatment period, control obese rats consumed larger amounts of food than control lean animals $(P<0.01)$. DZ obese rats demonstrated a significant reduction in food intake compared with control obese rats $(P<0.01)$ while DZ had little effect on food intake in lean animals.

\section{Effect of diazoxide on plasma glucose, lipids and insulin}

Table 2 shows fasting plasma levels of glucose, insulin, FFA, cholesterol and triglycerides, following 4 weeks of DZ or vehicle treatment. Fasting plasma glucose and insulin concentrations were significantly higher among control obese animals compared with lean rats $(P<0.001)$. Fasting plasma levels of glucose, insulin, FFA and triglycerides were significantly decreased in DZ obese animals compared with controls $(P<0.001)$. In lean animals, however, only plasma FFA $(P<0.001)$ and insulin $(P<0.001)$ were significantly decreased by DZ treatment.

\section{Effect of diazoxide treatment on Glut-2}

Figure 1 shows Western blot analysis of hepatic Glut-2 in obese and lean Zucker animals. There was no significant difference in Glut-2 protein between obese and lean controls. DZ treatment appeared to have no significant effect on Glut-2 protein levels in either obese or lean rats compared with their controls.

\section{Effect of diazoxide treatment on hepatic GK, G-6-Pase, PEPCK and X-5-P}

Figure 2 illustrates activities of key glycolytic and gluconeogenic enzymes and hepatic X-5-P in fasted obese and lean animals. Control obese rats had higher GK activity than control lean animals $(P<$ 0.0001). Similarly, control obese animals demonstrated higher G-6-Pase activity than control lean rats $(P<$

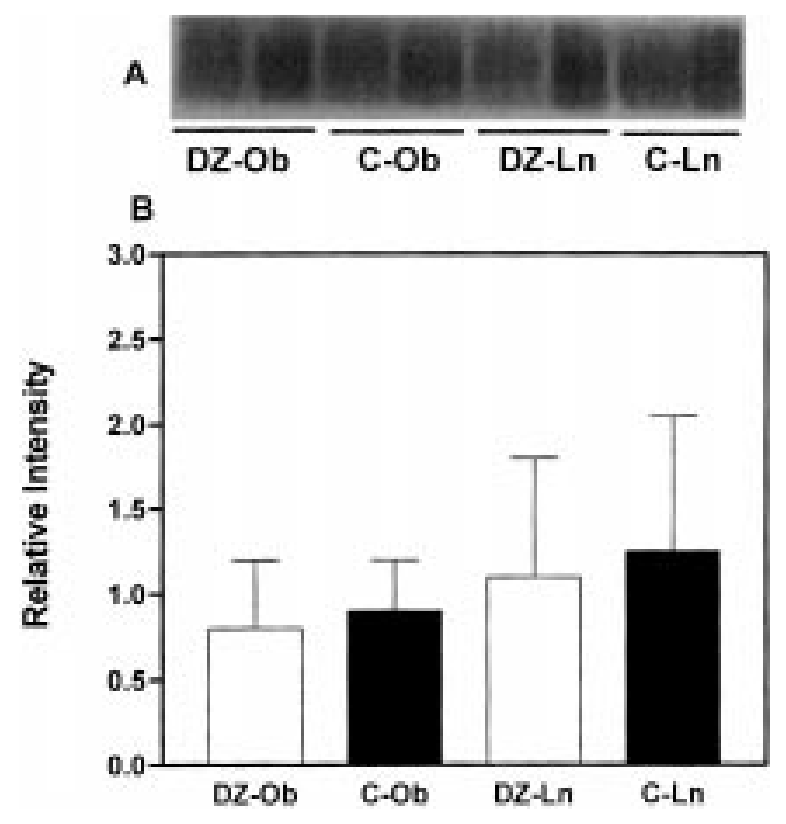

Figure 1 Hepatic Glut-2 from plasma membrane preparations in the obese $(\mathrm{Ob})(\mathrm{DZ}$, diazoxide; C, control) and lean (Ln) (DZ, diazoxide; $C$, control) Zucker rats. (A) A representative immunoblot containing samples from each of the four treatment groups. (B) Illustration of relative intensity of the Glut-2 band in each lane normalized to that of the standard sample. Data are means \pm S.E.

0.01). DZ treatment lowered GK and G-6-Pase activities in obese animals compared with their controls $(P<$ 0.001) without a significant effect in lean rats.

Obese animals had higher PEPCK activity than lean rats $(P<0.001)$. While DZ treatment resulted in significant reduction of PEPCK activity in obese rats compared with controls $(P<0.001)$, it increased PEPCK activity in lean animals $(P<0.002)$.

Obese animals demonstrated significantly higher liver X-5-P content than lean animals $(P<0.001)$ in the fasting state. However, DZ-treated animals did not demonstrate any significant change in their hepatic X-5-P content compared with their respective controls.

Table 2 Biochemical data in obese and lean Zucker rats. Data are means \pm s.E.

\begin{tabular}{|c|c|c|c|c|c|c|}
\hline Subgroup & $n$ & $\begin{array}{l}\text { Plasma glucose } \\
\text { (mmol/liter) }\end{array}$ & $\begin{array}{l}\text { Plasma insulin } \\
\quad(\mathrm{pmol} / \mathrm{ml})\end{array}$ & $\begin{array}{l}\text { Plasma FFA } \\
\text { (meq/liter) }\end{array}$ & $\begin{array}{l}\text { Plasma cholesterol } \\
\text { (mmol/liter) }\end{array}$ & $\begin{array}{c}\text { Plasma triglycerides } \\
\text { (mmol/liter) }\end{array}$ \\
\hline DZ obese & 8 & $6.43 \pm 0.11^{a}$ & $0.33 \pm 0.02$ & $0.79 \pm 0.12$ & $2.45 \pm 0.20$ & $4.50 \pm 0.53^{a}$ \\
\hline C obese & 8 & $8.91 \pm 0.22$ & $0.69 \pm 0.04$ & $1.51 \pm 0.13$ & $2.55 \pm 0.14$ & $9.23 \pm 1.29$ \\
\hline DZ lean & 8 & $5.83 \pm 0.17$ & $0.13 \pm 0.03$ & $0.21 \pm 0.05$ & $1.69 \pm 0.13$ & $1.61 \pm 0.33$ \\
\hline C lean & 8 & $6.49 \pm 0.33$ & $0.21 \pm 0.02$ & $0.46 \pm 0.06$ & $1.75 \pm 0.11$ & $1.54 \pm 0.27$ \\
\hline \multicolumn{7}{|l|}{$P$ value } \\
\hline Obese vs lean & & $<0.001$ & $<0.001$ & $<0.001$ & $<0.01$ & $<0.001$ \\
\hline
\end{tabular}

Data were analyzed by two-way ANOVA.

${ }^{a} \mathrm{Dz}$ obese vs C obese.

NS, not significant. 

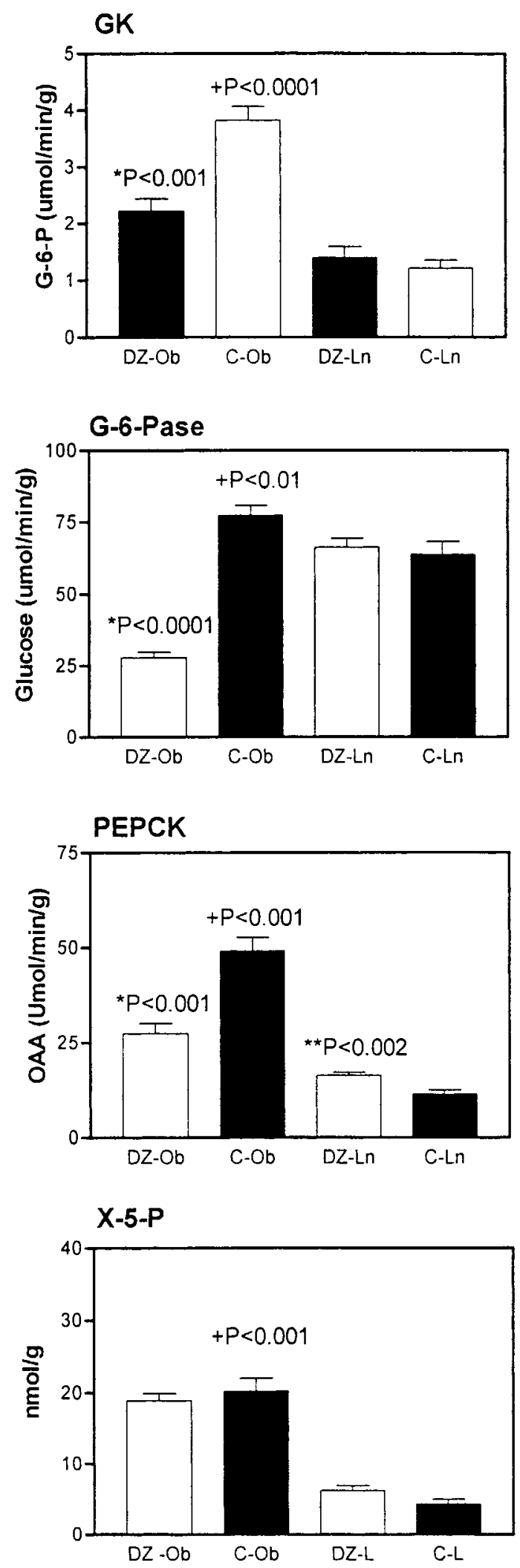

\section{Effect of diazoxide treatment on hepatic GS, GPa, G-6-P and glycogen content}

Figure 3 illustrates the activity of GS and GPa and hepatic G-6-P and glycogen contents. Obese animals exhibited higher GS (active, a) $(P<0.0001)$ activity, liver G-6-P $(P<0.001)$ and glycogen contents $(P<$ $0.0001)$ than control lean rats. Similarly, hepatic GPa activity was higher in control obese than in lean rats $(P<0.0001)$ in the fasting state. DZ treatment increased GSa activity $(P<0.0001)$, hepatic G-6-P $(P<0.01)$ and glycogen contents $(P<0.02)$ in obese and lean animals compared with their respective controls despite a significant increase in GPa activity in obese $(P<0.02)$ and lean $(P<0.001)$ rats.

\section{Discussion}

Consistent with our previous studies, DZ treatment of hyperinsulinemic obese Zucker rats decreased insulin secretion, food intake and rate of weight gain and this was accompanied by decreased plasma concentrations of glucose, FFA and triglycerides (23-25). DZ treatment resulted in suppression of the activities of glycolytic and gluconeogenic enzymes in hyperinsulinemic obese rats. The activities of GK, G-6-Pase, and PEPCK were suppressed which led to increased hepatic glycogen synthesis. In vitro and in vivo studies have shown that increasing concentrations of insulin not only alters insulin receptor affinity but also down-regulates the number of insulin receptors as the chronic hyperinsulinemic state develops (38-41). The liver of obese Zucker rats exhibits an abnormal regulation of glucose production, together with a glycolysis that is continuously overstimulated by hyperinsulinemia and never becomes insulin-resistant (42). This results in a significant increase in hepatic lipid synthesis and increase in very low-density lipoprotein (VLDL) secretion in obese animals (43). As adipose tissue lipoprotein lipase activity always remains higher than normal in obese rats (44), increased VLDL is accompanied by increased triglyceride accumulation within adipocytes leading to an unabated lipogenic state and obesity (43). While DZ lowers the rate of weight gain, in part by its anorectic effect in obese animals, it is also believed to exert its anti-obesity effect by down-regulating fatty acid synthase activity and lipoprotein lipase gene expression in adipose tissue (45), the key enzymes regulating lipogenesis. The DZ effect on fatty acid synthase activity is

Figure 2 Activities of hepatic GK, G-6-Pase, and PEPCK and hepatic X-5-P content in the obese (Ob) (DZ, diazoxide; C, control) and lean (Ln, L) (DZ, diazoxide; C, control) Zucker rats. Data are expressed as means \pm S.E. ${ }^{*} P<0.001$ or ${ }^{*} P<0.0001$ (DZ obese vs $C$ obese); ${ }^{* \star} P<0.002$ (DZ lean vs $C$ lean); ${ }^{+} P<0.01$, ${ }^{+} P<0.001$, or ${ }^{+} P<0.0001$ (C obese vs $C$ lean). 

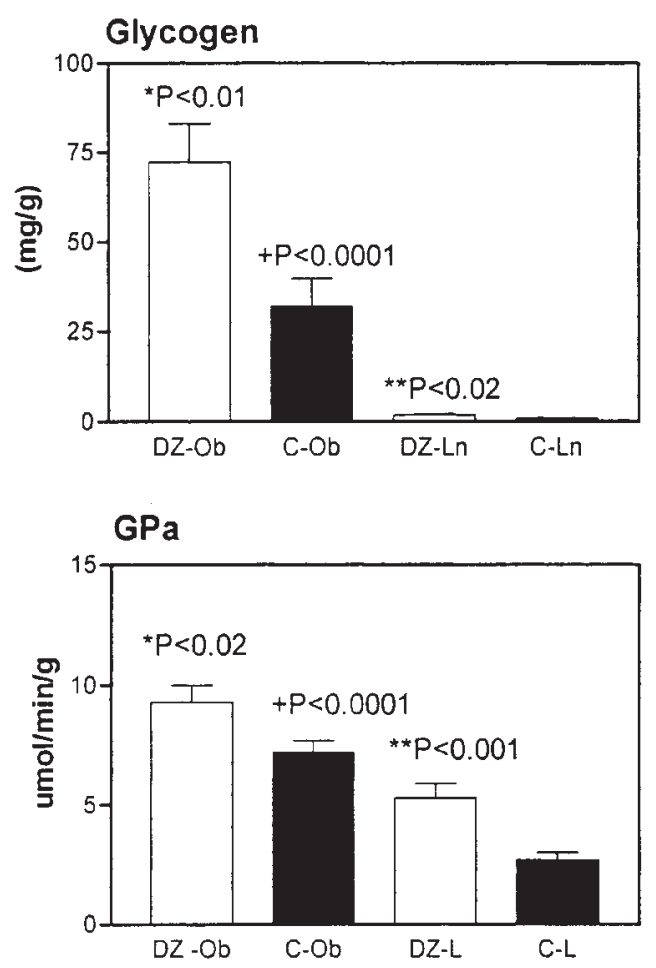

GS a

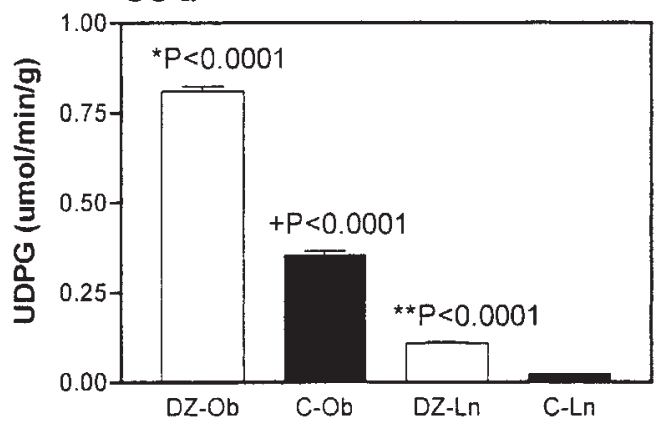

G-6-P

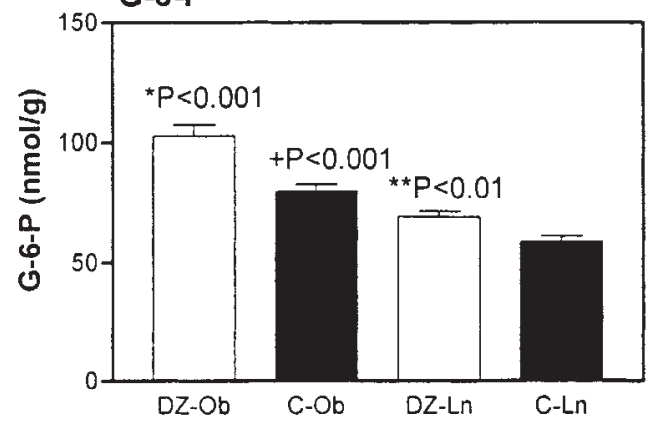

Figure 3 Activities of hepatic GSa and GPa along with hepatic G-6-P and glycogen contents in the obese $(\mathrm{Ob})(\mathrm{DZ}$, diazoxide; $\mathrm{C}$, control) and lean (LN, L) (DZ, diazoxide; C, control) Zucker rats. Data are expressed as means \pm S.E. ${ }^{*} P<0.02,{ }^{*} P<0.01$, ${ }^{\star} P<0.001$ or ${ }^{*} P<0.0001$ (DZ obese vs C obese); ${ }^{* *} P<0.02$ ${ }^{* \star} P<0.01,{ }^{* \star} P<0.001$ or ${ }^{* \star} P<0.0001$ (DZ lean vs $C$ lean); ${ }^{+} P<0.001$ or ${ }^{+} P<0.0001$ (C obese vs $C$ lean). believed to be, in part, due to its direct modulation of intracellular $\mathrm{Ca}^{2+}$ through $\mathrm{K}^{+}$-ATP channels (45).

Decreased insulin-stimulated glucose uptake is a characteristic of insulin resistance in obesity and diabetes (46) and defects in the glucose transport system could represent a significant contribution to the mechanisms of insulin resistance in liver and muscle (47, 48). The obese Zucker rat does not normally develop overt diabetes and is a better model of impaired glucose tolerance than diabetes (21). In agreement with Slieker et al., we did not observe any differences in hepatic Glut-2 protein levels between lean and obese animals (49). DZ treatment did not significantly affect hepatic Glut-2 levels in obese or lean animals.

Similar to previous studies, obese rats demonstrated higher GK activity and hepatic G-6-P than lean animals, presumably due to their prevailing hyperinsulinemia $(42,50)$. On the other hand, insulin suppression of hepatic G-6-Pase is believed to be less efficient in the insulin-resistant state which results in increased substrate flux through this enzyme constituting a key feature of type 2 DM (51). In our study, mildly hyperglycemic obese animals demonstrated higher G-6-Pase activity than the lean rats in the fasted state which was a consequence of enhanced enzyme induction by higher circulating glucose concentrations $(52,53)$. DZ suppression of circulating insulin in obese rats was associated with decreased GK activity due to reduced induction by insulin. However, the reduction in G-6-Pase activity in DZ obese animals was probably due to enhanced insulin sensitivity and decreased glycemia resulting in attenuation of G-6-Pase induction. Recently, Aoki et al. demonstrated that treatment of hyperinsulinemic and insulin-resistant diabetic $\mathrm{db} / \mathrm{db}$ mice and their heterozygote $(\mathrm{db} / \mathrm{db} / \mathrm{m})$ littermates with troglitazone, an insulin sensitizer, resulted in decreased plasma insulin and glucose levels and hepatic G-6-Pase activity (54). This was associated with increased hepatic G-6-P and glycogen content and GSa activity suggesting increased hepatic glucose uptake and glycogen synthesis. These findings support a tight correlation between hepatic glycogen content and G-6-Pase activity at any given time as previously shown (55) and are consistent with our observations in DZ obese rats. On the other hand, the lack of a DZ effect on GK and G-6-Pase activities in lean rats, despite the increase in GS activity and glycogen content, is probably due to opposing effects of enhanced hepatic glucose uptake and mild hyperglycemia $(23,24)$ on these enzymes.

It is well established that the net glycogen accumulation is the result of the balance between its synthesis by GS and its degradation by GPa (56). In our study, the hepatic GPa activity was higher in obese than in lean animals as previously shown by Aiston et al. (57). It has been suggested that enhanced glycogenolysis resulting from elevated GPa levels might be a consequence of hepatic insulin resistance or of dysregulation 
of insulin counter-regulatory hormones (42). Nevertheless, the net glycogen accumulation is believed to be increased due to enhanced insulin-induced phosphorylase phosphatase activity which results in inactivation of GPa in obese rats (58). DZ suppression of insulin in obese and lean animals not only augmented hepatic GS activity and glycogen content but also increased GPa activity which indicates an appropriate metabolic response to enhanced glycogen synthesis and reduced circulating insulin levels in these animals. These metabolic effects of DZ on enzymes regulating glycogen metabolism are believed to be mediated through changes in circulating insulin levels and insulin sensitivity. On the other hand, a direct effect of DZ on hepatic glucose metabolism, although possible, does not appear likely. For instance, it has been shown that high hepatic $\mathrm{GPa}$ activity may be due to persistently active phosphorylase kinase which may be maintained by high concentrations of intracellular $\mathrm{Ca}^{2+}$ in the obese state $(59,60)$. Since DZ is a $\mathrm{K}^{+}$-ATP channel agonist it decreases cellular $\mathrm{Ca}^{2+}$ influx (61), and therefore it is expected to result in an opposite effect by decreasing instead of increasing hepatic GPa activity.

The ability of liver cells to sense glucose and to coordinately modify the gene expression of several key enzymes may represent an important feedback control system in response to sustained changes in the rate of glucose flux and/or metabolism. Indeed, the expression of glycolytic and lipogenic enzymes is increased whereas that of a pivotal gluconeogenic enzyme, PEPCK, is decreased by glucose. While in the nondiabetic state PEPCK expression is suppressed with increasing glucose concentration, elevated PEPCK activity is observed in the insulin-resistant state (type 2 DM) (62). This glucose-sensing mechanism appears to be impaired in obese Zucker rats which demonstrate higher PEPCK activity and hepatic glucose production than lean rats (21). However, Perez et al. demonstrated that GK mRNA of obese rats remained elevated after $24 \mathrm{~h}$ of food deprivation and this was associated with a compensatory increase in hepatic PEPCK mRNA (22). They suggested starvation-induced changes in regulatory enzymes might be due to the hyperinsulinemic state which can lead to persistent stimulation of glycolysis. Although DZ treatment is shown to have an anorectic effect only in obese rats, DZ suppression of hyperinsulinemia in obese animals decreased PEPCK activity probably due to an enhanced inhibitory effect of insulin. On the other hand, DZ-induced hypoinsulinemia in lean rats increased PEPCK activity. Massillon et al. have suggested that PEPCK gene expression may also be regulated by intrahepatic glucose metabolism at or beyond G-6-P and by a pentose entering the nonoxidative branch of the pentose phosphate pathway (63). However, we found that higher hepatic G-6-P and pentose, X-5-P, in obese rats appeared to have no apparent inhibitory effect on PEPCK activity compared with lean animals. While
DZ treatment increased hepatic G-6-P content, it had no significant effect on hepatic X-5-P content and it resulted in diverse effects on hepatic PEPCK activity in these animals. These findings suggest that circulating insulin levels probably play a greater role in the regulation of PEPCK than hepatic G-6-P content and products of the nonoxidative branch of the pentose pathway. In support of our observations in DZ obese rats, Carr et al. recently demonstrated that DZ suppression of hyperinsulinemia in obese Zucker rats enhanced insulin sensitivity and reduced hepatic glucose production in DZ-treated obese Zucker rats by utilizing a hyperinsulinemic euglycemic clamp (64).

In conclusion, attenuation of hyperinsulinemia by DZ in obese Zucker rats resulted in reduced food intake, decreased rate of weight gain and improved glucose tolerance. These effects were accompanied by suppression of hepatic gluconeogenic activity and enhancement of glycogen synthesis, implying that modulation of hyperinsulinemia and insulin resistance by DZ may be therapeutically beneficial in obesity. However, further studies are indicated to assess the effect of short-term DZ treatment on hepatic glucose metabolism during fasting and refeeding in obese and lean Zucker rats.

\section{References}

1 Felber JP, Golay A, Felley C \& Jéquier E. Regulation of glucose storage in obesity and diabetes: metabolic aspects. Diabetes/ Metabolism Review $19984691-700$.

2 Defronzo RA. The triumvirate: $\beta$-cell, muscle, liver. A collusion responsible for NIDDM. Diabetes 198837 667-687.

3 Reaven GM. Role of insulin resistance in human disease. Diabetes $1988371595-1607$.

4 Cooney GJ, Astbury LD, Williams PF \& Caterson ID. Insulin response in individual tissue of control and gold thioglucoseobese mice in vivo with $\left[\mathrm{I}^{14} \mathrm{C}\right] 2$-deoxyglucose. Diabetes 198736 152-158.

5 Caterson ID, Astbury LD, Williams PF, Vanner MA, Conney JG \& Turtle JR. The activity of pyruvate dehydrogenase complex in heart and liver from mice during the development of obesity and insulin resistance. Biochemical Journal $1987 \mathbf{2 4 3} 549-553$.

6 Shulman GI, Rothman DL, Jue T, Stein P, DeFronzo RA \& Shulman RG. Quantitation of muscle glycogen synthesis in normal subjects and subjects with non-insulin-dependent diabetes by ${ }^{13} \mathrm{C}$ nuclear magnetic resonance spectroscopy. New England Journal of Medicine $1990322223-228$.

7 Taylor R \& Agius L. The biochemistry of diabetes. Biochemical Journal $1988 \mathbf{2 5 0} 625-640$.

8 McGarry JD. What if Minkowski had been ageusic? An alternative angle on diabetes. Science $1992 \mathbf{2 5 8} 766-770$.

9 Pilkis SJ \& Granner DK. Molecular physiology of the regulation of hepatic gluconeogenesis and glycolysis. Annual Review of Physiology 1992 54 885-909.

10 Bell GI, Burant CF, Takeda J \& Gould GW. Structure and function of mammalian facilitative sugar transporters. Journal of Biological Chemistry $199326819161-19164$.

11 Iynedjian PB. Mammalian glucokinase and its gene. Biochemical Journal $19932931-13$.

12 Agius L. The physiologic role of glucokinase binding and translocation in hepatocytes. Advanced Enzyme Regulation $1998 \mathbf{3 8}$ 303-331.

13 Vaulont S \& Kahn A. Transcriptional control of metabolic regulation by carbohydrates. FASEB Journal 19948 28-35. 
14 Decaux JF, Marcillat O, Richard AL, Henry J \& Kahn A. Glucosedependent and -independent effect of insulin on gene expression. Journal of Biological Chemistry 1991266 3432-3438.

15 Brown KS, Kalinowski SS, Megill JR, Durham SK \& Mookhtiar KA. Glucokinase regulatory protein may interact with glucokinase in the hepatocyte nucleus. Diabetes 199746 179-186.

16 Nordlie R, Bode AM \& Foster JD. Recent advances in hepatic glucose-6-phosphate regulation and function. Proceedings of the Society for Experimental Biology and Medicine 1993203 $274-285$.

17 Hanson RW \& Patel YM. Phosphoenolpyruvate carboxykinase (GTP): the gene and the enzyme. Advances in Enzymology 1994 $69203-281$.

18 Barzilai N \& Rossetti L. Role of glucokinase and glucose-6-phosphatase in the acute and chronic regulation of hepatic glucose fluxes. Journal of Biological Chemistry 1993268 25019-25025.

19 Gardner LB, Liu Z \& Barrett EJ. The role of glucose-6-phosphatase in the action of insulin on hepatic glucose production in the rat. Diabetes 199342 1614-1620.

20 Liu JS, Park EA, Gurney AL, Roesler WJ \& Hanson RW. Cyclic AMP induction of phospoenolpyruvate carboxykinase (GTP) gene transcription is mediated by multiple promoter elements. Journal of Biological Chemistry 1991266 19095-19102.

21 Triscari J, Stern JS, Johnson PR \& Sullivan AC. Carbohydrate metabolism in lean and obese Zucker rats. Metabolism 197928 $183-189$.

22 Perez JX, Manzano A, Tauler A \& Bartrons R. Effect of starvation on gene expression of regulatory enzymes of glycolysis/gluconeogenesis in genetically obese $(f a / f a)$ Zucker rats. International Journal of Obesity and Related Disorders 199822 667-672.

23 Alemzadeh R, Slonim AE, Zdanowicz MM \& Maturo J. Modification of insulin resistance by diazoxide in obese Zucker rats. Endocrinology 1993133 705-712.

24 Alemzadeh R, Jacobs W \& Pitukcheewanont P. Antiobesity effect of diazoxide in obese Zucker rats. Metabolism 199645 334-341.

25 Alemzadeh R \& Holshouser S. Effect of diazoxide on brain capillary insulin receptor binding and food intake in hyperphagic obese Zucker rats. Endocrinology 1999140 3197-3202.

26 Neville DM Jr. Isolation of an organ specific protein antigen from cell-surface membrane of rat liver. Biochimica et Biophysica Acta $1968154540-552$.

27 Davidson AL \& Arion WJ. Factors underlying significant underestimation of glucokinase activity in crude liver extracts: physiological implication of higher cellular activity. Archives of Biochemistry and Biophysics 1987253 156-167.

28 Lowry OH, Rosebrough NJ, Farr AL \& Randall RJ. Protein measurement with the folin phenol reagent. Journal of Biological Chemistry 1951193 265-275.

29 Lackner R, Challiss RAJ, West D \& Newsholme EA. A problem with the radiochemical assay of glucose-6-phosphatase in muscle. Biochemical Journal 1984218 649-651.

30 Lange JL, Arion WJ, Burchell A \& Burchell B. Aluminum ions are required for stabilization of hepatic microsomal glucose-6-phosphate by sodium fluoride. Journal of Biological Chemistry 1986 261 101-107.

31 Wiese TJ, Lambeth DO \& Ray PD. The intracellular distribution and activities of phosphoenolpyruvate carboxykinase isozymes in various tissues of several mammals and birds. Comparative Biochemistry and Physiology 1991 100B 297-302.

32 Thorburn A, Andrikopoulos S \& Proietto J. Defects in liver and muscle glycogen metabolism in neonatal and adult New Zealand obese mice. Metabolism $1995 \mathbf{4 4} 1298-1302$.

33 Nuttall FQ \& Gannon MC. An improved assay for hepatic glycogen synthase in liver extracts with emphasis on synthase R. Annals of Biochemistry $1989 \mathbf{1 7 8} 311-319$.

34 Nuttall FQ, Theen JW, Niewoehner C \& Gilboe DP. Response of liver glycogen synthase and phosphorylase to in vivo glucose and glucose analogues. American Journal of Physiology 1983 245 E521-E527.
35 Lang G \& Michal G. D-glucose-6-phosphate and D-fructose-6phosphate. In Methods of Enzymatic Analysis, pp 1238-1242. Ed. HU Bergmeyer. Weinheim: Verlag Chemie and New York: Academic Press, 1974.

36 Keppler D \& Decker K. Glycogen. In Methods of Enzymatic Analysis, pp 11-18. Ed. HU Bregmeyer. Weinheim: Verlag Chemie, 1991.

37 Casazza JP \& Veech RL. The measurement of xylulose 5-phosphate, ribulose 5-phosphate, and combined sedoheptulose 7-phosphate and ribose 5-phosphate in liver tissue. Annals of Biochemistry $1986159243-248$.

38 Terretaz J \& Jeanrenaud B. In vivo hepatic and peripheral insulin resistance in genetically obese (fa/fa) rats. Endocrinology 1987 $1121346-1351$.

39 Defronzo RA. Insulin secretion, insulin resistance, and obesity. International Journal of Obesity 19826 (Suppl 1) 73-82.

40 Gavin JR 3rd, Roth J, Neville DM, DeMeyts P \& Buell DN. Insulindependent regulation of insulin receptor concentrations in cell culture. PNAS $19747184-88$.

41 Clark JB, Keen S \& Clark CM Jr. Studies on regulation of insulin binding by liver plasma membrane from Zucker fatty rats. Diabetes $198231867-873$

42 Van de Werve G \& Jeanrenaud B. The onset of liver glycogen synthesis in fasted-refed lean and genetically obese $(f a / f a)$ rats. Diabetologia $198730169-174$.

43 Jeanrenaud B, Halimi S \& Van de Werve G. Neuroendocrine disorders seen as triggers of the triad: obesity-insulin resistanceabnormal glucose tolerance. Diabetes/Metabolism Review 1 $261-291$.

44 Gruen RK \& Greenwood MR. Adipose tissue lipoprotein lipase and glycerol release in fasted Zucker $(f a / f a)$ rats. American Journal of Physiology 1981241 E76-E83.

45 Standridge M, Alemzadeh R, Koontz J \& Moustaid N. Diazoxide down-regulates leptin and lipid metabolizing enzymes in adipose tissue of Zucker rats. FASEB Journal $2000 \mathbf{1 4} 455-460$.

46 Kubo K \& Foley JE. Rate-limiting steps for insulin-mediated glucose uptake into perfused rat hind limb. American Journal of Physiology 1986250 E100-E102.

47 Rothman DL, Shulman RG \& Shulman GI. NMR studies of muscle glycogen synthesis in normal and non-insulin-dependent diabetic subjects. Biochemical Society Transactions $199119992-994$.

48 Ziel FH, Venkatesan N \& Davidson MB. Glucose transport is rate limiting for skeletal muscle glucose metabolism in normal and STZ-induced diabetic rat. Diabetes 198837 885-890.

49 Slieker LJ, Sundell KL, Heath WF, Osborne HE, Bue B, Manetta J \& Sportsman R. Glucose transporter levels in tissue of spontaneously diabetic Zucker fa/fa rat (ZDF/drt) and viable yellow mouse (A $\left.\mathrm{A}^{\mathrm{vy}} / \mathrm{a}\right)$. Diabetes $1992 \mathbf{4 1} 187-193$.

50 Huupponen R, Karvonen I \& Sotaniemi E. Activity of hepatic glucose phosphorylating and NADPH generating enzymes in Zucker rats. Diabetes Research 198910 143-146.

51 Ferrannini E \& Groop L. Hepatic glucose production in insulinresistant states. Diabetes/Metabolism Review 19895 711-725.

52 Argaud D, Kirby TL, Newgard CB \& Lange AJ. Stimulation of glucose-6-phosphatase gene expression by glucose and fructose2,6-bisphosphate. Journal of Biological Chemistry 1997272 $12854-12861$.

53 Massillon D, Barzilai N, Chen W, Hu M \& Rossetti L. Glucose regulates in vivo glucose-6-phosphatase gene expression in the liver of diabetic rats. Journal of Biological Chemistry 1996271 9871-9874.

54 Aoki K, Saito T, Satoh S, Mukasa K, Kaneshiro M, Kawasaki S, Okamura A \& Sekihara H. Dehydroepiandrosterone suppresses the elevated hepatic glucose-6-phosphatase and fructose-1,6bisphosphatase activities in C57BL/Ksj-db/db mice: comparison with troglitazone. Diabetes $1999 \mathbf{4 8} 1579-1585$.

55 Minassian C, Montano S \& Mithieux G. Regulatory role of glucose-6-phosphatase in the repletion of liver glycogen during refeeding in fasted rats. Biochimica et Biophysica Acta 1999 $1452172-178$. 
56 Chen Y-T \& Burchell A. Glycogen storage diseases. In Metabolic and Molecular Bases of Inherited Diseases, 7th edn, pp 935-948, Eds CR Scriver, AL Beaudet, WS Sly \& D Valle. New York, NY: McGraw-Hill, 1995.

57 Aiston S, Peak M \& Agius L. Impaired glycogen synthesis in hepatocytes from Zucker fatty $(f a / f a)$ rats: the role of increased phosphorylase activity. Diabetologia 200043 589-597.

58 Margolis RN. Hepatic glycogen synthase phosphatase and phosphorylase phosphatase are increased in obese $(f a / f a)$ hyperinsulinemic Zucker rats: effects of glyburide administration. Life Sciences 198714 2615-2622.

59 Fraser DR \& Trayhurn P. Mitochondrial $\mathrm{Ca}^{2+}$ transport in lean and genetically obese (ob/ob) mice. Biochemical Journal 1983 $214163-170$.

60 Van de Werve G, Assimacopoulos-Jeannet F \& Jeanrenaud B. Altered liver glycogen metabolism in fed genetically obese mice. Biochemical Journal 1983216 273-280.
61 Shi H, Moustaid-Mousa N, Wilkinson WO \& Zemel MB. Role of sulfonylurea receptor (SUR) in regulating human adipocyte metabolism. FASEB Journal 199913 1833-1838.

62 Granner DK \& O'Brien RM. Molecular physiology and genetics of NIDDM. Diabetes Care 199215 369-395.

63 Massillon D, Chen W, Barzilai N, Prus-Wertheimer D, Hawkins M, Liu R et al. Carbon flux via the pentose phosphate pathway regulates the hepatic expression of the glucose-6-phosphatase and phosphoenolpyruvate carboxykinase genes in conscious rats. Journal of Biological Chemistry $1998273228-234$.

64 Carr RD, Gronemann S, Hansen B, Press K, Sturis J \& Brand CL. Diazoxide improves insulin sensitivity in Zucker obese rats. Diabetologia 199841 (Suppl 1) A198.

Received 10 July 2001

Accepted 5 March 2002 